\title{
Nickel-Catalyzed Intermolecular Alkyne Hydrohydrazonation
}

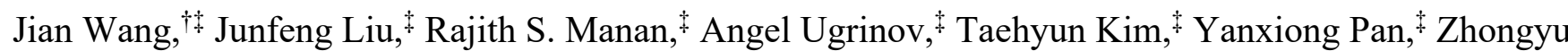 \\ Yang, ${ }^{\ddagger}$ and Pinjing Zhao*,\$ \\ †School of Pharmacy, Hangzhou Medical College, Hangzhou, Zhejiang Province, China \\ *Department of Chemistry and Biochemistry, North Dakota State University, Fargo, ND 58108-6050, United States \\ KEYWORDS: alkyne hydroamination, ketazine, hydrazone, hydrohydrazonation, nickel catalyst, $N$-heterocyclic carbene.
}

\begin{abstract}
We report a method for mild and atom-efficient synthesis of ketazines via nickel-catalyzed intermolecular hydroamination of internal alkynes with $\mathrm{NH}_{2}$-hydrazones. This alkyne hydrohydrazonation process is promoted by [Ni(cod) $\left.{ }_{2}\right]$ as a $\mathrm{Ni}(0)$ precatalyst and IPr as a N-heterocyclic carbene (NHC) ligand. A stoichiometric reaction between in situ generated [Ni(IPr) 2 ] and benzophenone hydrazone $\left(\mathrm{Ph}_{2} \mathrm{C}=\mathrm{NNH}_{2}\right)$ led to the isolation of IPr-coordinated and hydroxo-bridged dinuclear Ni(II) hydrazonato complex $\left[(\mathrm{IPr}) \mathrm{Ni}\left(\mathrm{HNN}=\mathrm{CPh}_{2}\right)\left(\mu_{2}-\mathrm{OH}\right)\right]_{2}$ that displayed high activity as a hydrohydrazonation pre-catalyst. We propose a catalytic cycle involving $\mathrm{C}-\mathrm{N}$ bond formation via alkyne insertion into the $\mathrm{Ni}-\mathrm{N}$ linkage of $\mathrm{Ni}$ (II) hydrazonato intermediates.
\end{abstract}

Hydrazones are important building blocks in organic synthesis due to their convenient preparation via hydrazinecarbonyl condensation and versatile reactivity with $\mathrm{C}=\mathrm{N}$ and $\mathrm{N}-\mathrm{N}$ functionality. ${ }^{1}$ Synthetic applications of hydrazones have conventionally focused on their conversions into carbanion intermediates driven by $\mathrm{N}_{2}$ release, exemplified by the classic Wolff-Kishner reduction. ${ }^{2}$ Recent developments in organometallic catalysis have significantly expanded the scope of hydrazone transformations. In particular, $\mathrm{N}$-functionalized hydrazones are established as activated imine-analogs for catalytic hydrogenations and nucleophilic additions. ${ }^{1 b, 1 c}$ For catalytic $\mathrm{C}-\mathrm{N}$ bond formation with hydrazones, a well-documented approach is the Buchwald-Hartwig amination of aryl halides with $\mathrm{N}$-unsubstituted hydrazones $\left(\mathrm{NH}_{2}\right.$-hydrazones). ${ }^{3}$ In comparison, limited progress has been made on the hydroamination approach, the formal addition of a hydrazone $\mathrm{N}-\mathrm{H}$ bond across an un-activated $\mathrm{C}-\mathrm{C} \pi$ bond. ${ }^{4}$ Reports on such "hydrohydrazonation" mainly involve intramolecular transformations that are thermodynamically driven by stable N-heterocycle formation. ${ }^{5,6}$ By contrast, intermolecular hydrohydrazonation with simple alkene/alkyne substrates remains underexplored..$^{7-9}$ In comparison to the more successful development of hydroamination with $\mathrm{NH}_{2}$-hydrazines (i.e. hydrohyrazination), ${ }^{4,5 c, 9-11}$ hydrohydrazonation faces the obstacles of lower reactivity for hydrazones as $\mathrm{NH}$-nucleophiles and basepromoted hydrazone decomposition under heating conditions. ${ }^{2}$

We report herein a nickel/N-heterocyclic carbene (NHC) catalyst system for intermolecular hydrohydrazonation of internal alkynes with $\mathrm{NH}_{2}$-hydrazones under mild conditions. This work is part of our continuous efforts to develop catalytic hydroamination processes following a prior study on $\mathrm{Ni} / \mathrm{NHC}-$ catalyzed alkyne hydroimination with $\mathrm{N}-\mathrm{H}$ ketimines. ${ }^{12}$ Recent reports on transition metal-catalyzed intermolecular $\mathrm{NH}_{2}$ hydrazone/alkyne couplings have focused on [4+2] and [3+2] annulations initiated by hydrazone-directed $\mathrm{C}-\mathrm{H}$ activation/cyclometalation and subsequent alkyne insertions (Scheme 1a). ${ }^{7,13,14}$ Notably, Bertrand and coworkers have reported $\mathrm{Au}$ - and $\mathrm{Cu}$-catalyzed hydrohydrazonation of terminal alkynes with methyl ketone-derived $\mathrm{NH}_{2}$-hydrazones at 100 ${ }^{\circ} \mathrm{C}$ (Scheme 1b), ${ }^{9}$ which was proposed to proceed by an outersphere pathway via nucleophilic attack to Lewis acidic metal $\pi$-alkyne complexes. ${ }^{4 \mathrm{e}}$ In comparison, the current $\mathrm{Ni} / \mathrm{NHC}$ catalyst enables coupling between various $\mathrm{NH}_{2}$-hydrazones (1) and internal alkynes (2) at reduced reaction temperatures of $23-80{ }^{\circ} \mathrm{C}$ (Scheme 1c). ${ }^{15}$ We also report preliminary mechanistic results that support a migratory insertion pathway for $\mathrm{C}-\mathrm{N}$ bond formation via $\mathrm{Ni}(\mathrm{II})$ hydrazonato intermediates. Thus, the current method expands the scope of base metal-catalyzed hydroamination ${ }^{4}$ and provides atom-efficient access to valuable azine products (3). ${ }^{16}$ Furthermore, this work provides new mechanistic insight into $\mathrm{Ni} / \mathrm{NHC}$-catalyzed transformations as a versatile toolbox for organic synthesis. ${ }^{17}$

Our study began with a model reaction between benzophenone hydrazone (1a) and diphenylacetylene (2a). With prior results on alkyne hydroimination, ${ }^{12}$ we chose to focus on $\mathrm{Ni} / \mathrm{NHC}$ catalyst systems with $\left[\mathrm{Ni}(\operatorname{cod})_{2}\right](4)$ as a $\mathrm{Ni}(0)$ precatalyst to evaluate reaction parameters by GC analysis. Key results from the catalyst development are summarized in Table 1 and more details are described in Table S1-S2 in Supporting Information. Under previously reported hydroimination conditions, ${ }^{12}$ a reaction between $0.50 \mathrm{mmol} \mathbf{1 a}$ and 1.5 equiv $\mathbf{2 a}$ was promoted by $10 \mathrm{~mol} \%$ 4, $22 \mathrm{~mol} \%$ IPr ligand (5a) and 1 equiv $\mathrm{Cs}_{2} \mathrm{CO}_{3}$ in $m$-xylene to form ketazine product $\mathbf{3 a}$ in $78 \%$ yield after heating at $120{ }^{\circ} \mathrm{C}$ for 24 hours (entry 1). Replacing IPr with other NHC ligands, such as the structurally related IMes (5b), SIPr (5c) and IPr*OMe (5d), ${ }^{18}$ led to significantly reduced catalyst reactivity (entries 2-4). In contrast, removing $\mathrm{Cs}_{2} \mathrm{CO}_{3}$ or replacing it with various inorganic bases did not have major impacts (entries 5-9). Thus, solvent effects on reactivity were studied without using base additives (entries 913 ), and toluene was found to give the highest 3a yield of $81 \%$. Further catalyst development involved changing catalyst/ligand loadings, reaction temperatures, and reagent stoichiometry (entries 14-18). In general, 3a was detected as a dominant $(E)$-stereoisomer ( $>50: 1$ selectivity) regarding the deoxybenzoin hydrazone moiety, which is sterically less 
strained than the corresponding $(Z)$-isomer. The structure of isolated 3a was established by NMR spectroscopy and X-ray crystallography (vide infra). Under the optimized conditions of heating at $80{ }^{\circ} \mathrm{C}$ in toluene solvent, reaction between $1 \mathbf{a}$ and 2a (1.2 equiv) was promoted by $5 \mathrm{~mol} \% 4$ and $11 \mathrm{~mol} \% 5$ a to form 3a in $81 \%$ yield over 24 hours (entry 15). Small amounts of byproducts $(<10 \%)$ from hydrazone decomposition and alkyne oligomerization ${ }^{19}$ were detected under these conditions. The loadings of $\mathbf{4}$ and $5 \mathbf{a}$ could be reduced to 1 and $2 \mathrm{~mol} \%$ to form $\mathbf{3 a}$ in $73 \%$ yield over 48 hours (entry 17). In addition, higher loadings of $15 \mathrm{~mol} \% 4$ and $31 \mathrm{~mol} \%$ 5a promoted the reaction at room temperature $\left(\sim 23{ }^{\circ} \mathrm{C}\right)$ to form $\mathbf{3 a}$ in $79 \%$ yield after 96 hours (entry 18). It should be noted that roomtemperature intermolecular alkyne hydroamination is only known for Au-based catalysts and limited to terminal alkynes. $^{10,20}$ Lastly, the gram-scale hydrohydrazonation was demonstrated with a 10 -fold scale-up of the optimized model reaction to give $\mathbf{3 a}$ in $78 \%$ yield (entry 19, $1.46 \mathrm{~g}$ isolated).

Under the standard reaction conditions at $80{ }^{\circ} \mathrm{C}$, various $\mathrm{NH}_{2}$-hydrazones (1) and internal alkynes (2) were studied for Ni-catalyzed hydrohydrazonation (Table 2). ${ }^{21}$ In general, the reactions led to selective formation of ketazines $(3)$ to the exclusion of possible annulation byproducts, ${ }^{13,14}$ and most ketazines were formed as the less sterically strained stereoisomer in high selectivity $(>20: 1)$. Alkyne substrate scope and structural effects on hydrohydrazonation reactivity were evaluated with benzophenone hydrazone (1a) to generate products $\mathbf{3 a - g}$. Symmetrical diaryl alkynes with electron-donating alkyl substituents at para- or meta-positions led to ketazine products $\mathbf{3 b}$ and $\mathbf{3 c}$ in high yields. In comparison, the electron-deficient bis(para-trifluoromethylphenyl)acetylene displayed high reactivity but low ketazine production due to competitive alkyne trimerization. ${ }^{19}$ Thus, a modified procedure of slow alkyne addition and lower reaction temperature of $40{ }^{\circ} \mathrm{C}$ was developed to suppress trimerization, giving product $3 \mathbf{d}$ in $81 \%$ yield. As a probe for regioselectivity with electronically differentiated diarylacetylenes, a reaction between 1a and ( $p$ anisylethynyl)benzene was subjected to GC analysis. ${ }^{22}$ The result indicated formation of two ketazine isomers in $70 \%$ overall yield and 1.6:1 ratio (3e/3e'), favoring $\mathrm{C}-\mathrm{N}$ bond formation at the benzylic position of electron-rich para-anisyl over phenyl group. Reactions with symmetrical dialkylacetylenes face the dual challenges of competitive alkyne trimerization $^{19}$ and ketazine instability that hindered isolation attempts. Thus, a moderate yield of $63 \%$ for 4 -octyne-derived product $\mathbf{3 f}$ was obtained via GC analysis. ${ }^{22}$ Similarly, a GC yield of $60 \%$ was determined for product $\mathbf{3 g}$ from room-temperature hydrohydrazonation of 1,4-dimethoxy-2-butyne. 3f and $\mathbf{3 g}$ were both detected as a $\sim 1: 1$ mixture of E/Z-stereoisomers, which is anticipated with their similar steric environments. Reactions between 1a and 1-alkyl-2-arylacetylenes (e.g. 1-ethyl-2phenylacetylene) suffered from dominant alkyne trimerization $^{19}$ and generated only traces of desired ketazine products. ${ }^{23}$

Under standard hydrohydrazonation conditions, reactions between $\mathbf{2 a}$ and benzophenone hydrazone derivatives with para-methyl, -methoxy and -fluoro substituents gave ketazines 3h-j in good yields. In particular, 4,4'-dimethylbenzophenone hydrazone (1b) gave product $\mathbf{3 h}$ in $91 \%$ yield, which suggests enhanced hydrazone nucleophilicity by electron-donating alkyl substitution. The high reactivity of $\mathbf{1 b}$ was also displayed in its coupling with diarylacetylenes with para- ${ }^{i} \mathrm{Pr}$ or $-\mathrm{CF}_{3}$ substituents that formed ketazine $\mathbf{3 k}$ and $\mathbf{3 l}$ in $93 \%$ and $88 \%$ yields. In addition, $\mathbf{1 b}$ reacted with di(2-thienyl)acetylene to form ketazine isomers $\mathbf{3} \mathbf{m}$ and $\mathbf{3} \mathbf{m}$ ' in $93 \%$ combined yield and 3.3:1 stereoselectivity. ${ }^{24}$ Similar to benzophenone-derived $\mathrm{NH}_{2}$-hydrazone, the acetophenone- and benzil-derived analogs displayed good reactivity towards $\mathbf{2 a}$ to form ketazines $\mathbf{3 n}$ and 30 in high yields. In comparison, the sterically bulky and thermally unstable dicyclohexyl ketone hydrazone led to product $3 p$ in a moderate yield of $65 \%$. As demonstrated with the solid-state structures of 3a and 3n-p by X-ray crystallography, the stereochemistry of diphenylacetylene-derived ketazine products was mainly affected by steric factors to favor (E)-stereoisomer regarding the deoxybenzoin hydrazone moiety and twisted s-trans conformations.

In-depth reaction mechanism understanding for current hydrohydrazonation is hindered by the lack of suitable probes for regioselectivity ${ }^{23}$ as well as stereochemical information, which was due to product detection in ketazine forms rather than isomeric enamines forms that would indicate a formally synor anti-alkyne addition by the $\mathrm{N}-\mathrm{H}$ bond. ${ }^{4,25}$ In our prior study on alkyne hydroimination using a similar $\mathrm{Ni} / \mathrm{IPr}$ catalyst system, the stereospecific formation of $(Z)$-enamine-type products supported a proposed anti-attack at $\mathrm{Ni}(0)$-coordinated alkynes by $\mathrm{NH}$-imine nucleophiles. ${ }^{12}$ In addition, a room-temperature reaction between benzophenone imine and in situ generated $\left[\mathrm{Ni}(\mathrm{IPr})_{2}\right]$ via heating mixed $\left[\mathrm{Ni}(\mathrm{IPr})_{2}\right] / \mathrm{IPr}$ led to the formation of a $\mathrm{Ni}(0)$ bis(imine) complex, [(IPr) $\left.\mathrm{Ni}\left(\mathrm{HN}=\mathrm{CPh}_{2}\right)_{2}\right](6)$, that was catalytically active for alkyne hydroimination (Scheme 2a). In current study, a similar reaction between benzophenone hydrazone (1a) and in situ generated [Ni(IPr) 2$]$ led to a complex mixture of multiple Ni species. Attempted purification of such mixture by recrystallization did not generate analogous $\mathrm{Ni}(0)$ bis(hydrazone) complexes, but instead a hydroxobridged, dinuclear $\mathrm{Ni}(\mathrm{II})$ hydrazonato complex [(IPr)Ni( $\eta^{1}$ $\left.\left.\mathrm{H}_{2} \mathrm{NN}=\mathrm{CPh}_{2}\right)\left(\mu_{2}-\mathrm{OH}\right)\right]_{2}$ (7a). The solid-state structure of $7 \mathbf{a}$ was established by single crystal X-ray diffraction and featured relatively short $\mathrm{Ni}-\mathrm{N}$ bond length of $1.83 \AA$ for the $\mathrm{Ni}$ (II) hydrazonato moieties. ${ }^{26}$ The formation of $7 \mathbf{a}$ was likely initiated by aerobic oxidation of $\left[\mathrm{Ni}(\mathrm{IPr})_{2}\right]$ considering the high air-sensitivity of electron-rich, zero-valence metal bisNHC complexes. ${ }^{16,27}$ For example, Stahl and coworkers reported rapid aerobic oxidation of $\left[\mathrm{Pd}(\mathrm{IMes})_{2}\right]$ to form an $\eta^{2}-$ peroxo complex $\left[\mathrm{Pd}(\mathrm{IMes})_{2}\left(\mathrm{O}_{2}\right)\right] .{ }^{28}$ Thus, we propose a similar process of $\left[\mathrm{Ni}(\mathrm{IPr})_{2}\right]$ oxidation by trace $\mathrm{O}_{2}$ in solvent to form $\left[\mathrm{Ni}(\mathrm{IPr})_{2}\left(\eta^{2}-\mathrm{O}_{2}\right)\right]$ (A) (Scheme 2b) ${ }^{29}$ Subsequent reaction with another equivalent of $\left[\mathrm{Ni}(\mathrm{IPr})_{2}\right]$ generated dinuclear $\mathrm{Ni}(\mathrm{I})$ oxo complex B, which underwent IPr dissociation and dinuclear oxidative addition process with 1a to form 7a. Notably, the Sigman group has reported facile aerobic oxidation of a IPrligated $\mathrm{Ni}(\mathrm{II}) \pi$-allyl chloro complex to generate $\left[(\mathrm{IPr}) \mathrm{NiCl}\left(\mu_{2}-\mathrm{OH}\right)\right]_{2}$ as a close structural analog of $7 \mathbf{a}^{30}$

Using complex $7 \mathbf{a}$ to replace mixed $\left[\mathrm{Ni}(\operatorname{cod})_{2}\right] / \mathrm{IPr}$ under hydrohydrazonation conditions (Scheme 2c), the reaction between 1a and 2a was effectively promoted at a low catalyst loading of $0.5 \mathrm{~mol} \% \mathbf{7 a}$ to give $\mathbf{3 a}$ in $83 \%$ GC yield $(73 \%$ isolated). The same catalyst loading also enabled a 5-fold scale-up reaction to give 3a in 79\% isolated yield after heating at $80{ }^{\circ} \mathrm{C}$ for 48 hours. By increasing the loading of $7 \mathbf{a}$ to 5 $\mathrm{mol} \%$, the scale-up reaction could proceed without heating to give $\mathbf{3 a}$ in $71 \%$ yield. Thus, complex $\mathbf{7 a}$ is a more reactive catalyst precursor compared to mixed $\left[\mathrm{Ni}(\operatorname{cod})_{2}\right] / \mathrm{IPr}$, which presumably led to in situ generation of $\left[\mathrm{Ni}(\mathrm{IPr})_{2}\right]$ as a common pre-catalyst for $\mathrm{Ni} / \mathrm{NHC}$ catalysis. $^{31}$ 
Based on the isolation and high catalytic activity of complex 7a, we propose a Ni(II)-based catalytic cycle for alkyne hydrohydrazonation as shown in Scheme 2d. Under current catalytic conditions, oxidation by trace $\mathrm{O}_{2}$ of in situ $\mathrm{Ni}(\mathrm{IPr})_{2}$ and subsequent reaction with hydrazone substrate led to dinuclear Ni(II) complex 7. De-aggregation of 7 generated the IPrligated $\mathrm{Ni}$ (II) hydroxo hydrazonato monomer $\mathbf{C}$, which underwent sequential alkyne coordination and 1,2-insertion into the $\mathrm{Ni}-\mathrm{N}$ bond to form $\mathrm{Ni}(\mathrm{II})$ alkenyl intermediate $(\mathbf{C} \rightarrow \mathbf{D}$ and D $\rightarrow$ E). Subsequent protonation with $\mathrm{NH}_{2}$-hydrazone regenerated $\mathbf{C}$ to complete the catalytic cycle and released $\mathrm{N}$-iminyl enamine product 3', which underwent rapid isomerization to form the more stable ketazine $\mathbf{3}$ as detectable hydrohydrazonation product. We hasten to add that alkyne 1,2-insertion into a late transition metal-nitrogen $\sigma$-bond is not well-established as analogous alkene insertions, and the direct observations on such intermolecular amido transfer processes are limited to activated alkynes such as dimethyl acetylenedicarboxylate (DMAD).$^{32-35}$ Thus, we cannot exclude the possibility of alternative, $\mathrm{Ni}(0) / \mathrm{Ni}(\mathrm{II})$-based hydrohydrazonation mechanisms involving different $\mathrm{C}-\mathrm{N}$ bond formation processes that have been proposed for catalytic alkyne hydroamination. ${ }^{4} \mathrm{We}$ are particularly intrigued by the possibility of $\mathrm{Ni}(0)$-mediated $\mathrm{N}-\mathrm{H}$ oxidative addition of $\mathrm{NH}_{2}$-hydrazone that forms a $\mathrm{Ni}$ (II) hydrido hydrazonato intermediate. Subsequent alkyne insertion into the $\mathrm{Ni}-\mathrm{H}$ bond and $\mathrm{C}-\mathrm{N}$ bond formation by reductive elimination from the resulting $\mathrm{Ni}$ (II) alkenyl hydrazonate forms the hydrohydrazonation product (3') and regenerates $\mathrm{Ni}(0)$ catalyst. $^{36}$ This alternative mechanism would resonate with reported mild Buchwald-Hartwig amination with $\mathrm{NH}_{2}$ hydrazones using a similar Ni/IPr catalyst system, which involved $\mathrm{C}-\mathrm{N}$ reductive elimination from $\mathrm{Ni}(\mathrm{II})$ aryl hydrazonato intermediates. ${ }^{3 \mathrm{~d}}$ Getting definitive evidence to distinguish between possible hydrohydrazonation pathways would require a comprehensive mechanism investigation that we wish to pursue in the near future.

In summary, we have developed a $\mathrm{Ni} / \mathrm{NHC}$ catalyst system for intermolecular hydrohydrazonation of internal alkynes under mild and base-free conditions. Based on the high catalytic activity of an isolated $\mathrm{Ni}(\mathrm{II}) / \mathrm{NHC}$ complex, we propose a rare process of $\mathrm{C}-\mathrm{N}$ bond formation by alkyne insertion into the $\mathrm{Ni}-\mathrm{N}$ linkage of $\mathrm{Ni}(\mathrm{II})$ hydrazonato intermediates. Future studies will focus on in-depth mechanism understanding of this catalyst system for broader synthetic applications involving $\mathrm{N}-\mathrm{H}$ bond cleavage and $\mathrm{C}-\mathrm{N}$ bond formation processes.
Scheme 1. Transition Metal-Catalyzed Intermolecular Couplings between $\mathrm{NH}_{2}-\mathrm{Hydrazones}$ and Alkynes.

(a) Annulations via hydrazone-directed aromatic $\mathrm{C}-\mathrm{H}$ activation [refs 7, 12]

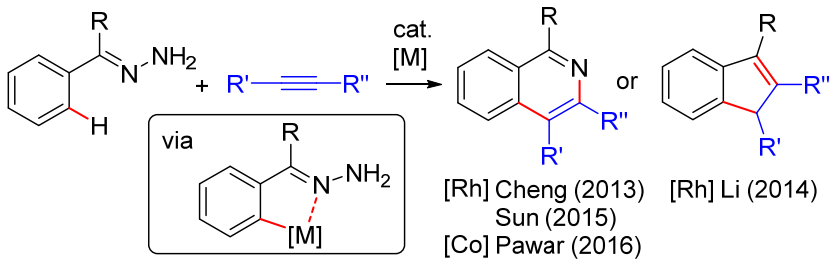

(b) Bertrand's reports on hydrohydrazonation of terminal alkynes [ref 9]

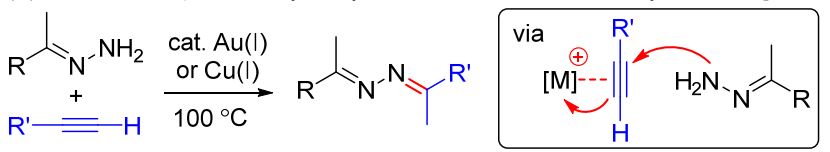

(c) This study. mild hydrohydrazonation of internal alkynes

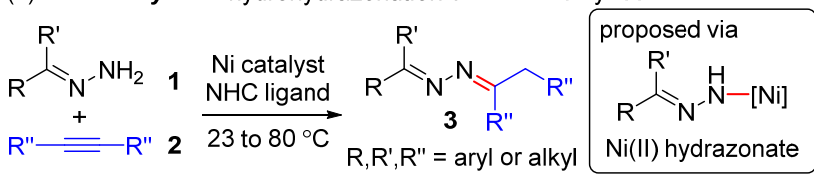

Table 1. Optimization of Alkyne Hydrohydrazonation. ${ }^{a}$

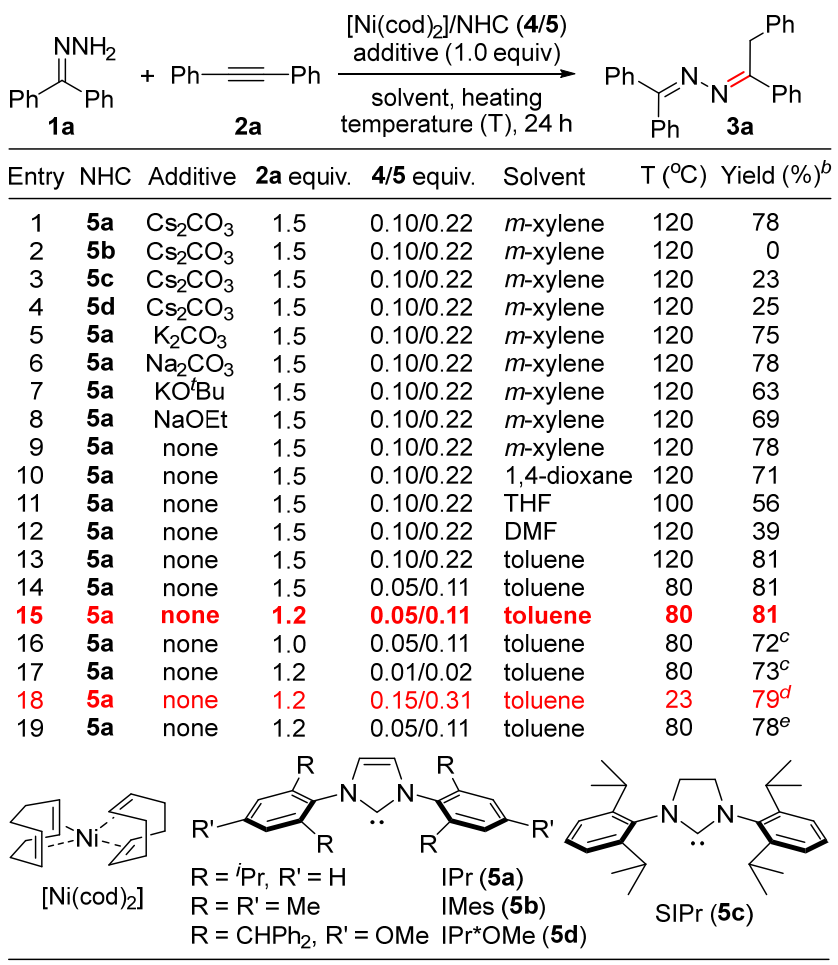

${ }^{a}$ General conditions: $\mathbf{1 a}(0.50 \mathrm{mmol}, 1.0$ equiv $), \mathbf{2 a},\left[\mathrm{Ni}(\operatorname{cod})_{2}\right]$ (4), NHC ligand (5), additive (1.0 equiv), solvent (2.0 mL), $24 \mathrm{~h}$. ${ }^{b}$ Yields determined by GC analysis. ${ }^{c} 48 \mathrm{~h}$ reaction time. ${ }^{d} 96 \mathrm{~h}$ reaction time. ${ }^{e}$ Isolated yield $(1.46 \mathrm{~g})$ from a scale-up reaction with $5.0 \mathrm{mmol} 1 \mathrm{a}, 10 \mathrm{~mL}$ toluene and $18 \mathrm{~h}$ reaction time. 
Table 2. Scope of Ketazine Products from of Ni-Catalyzed Alkyne Hydrohydrazonation.

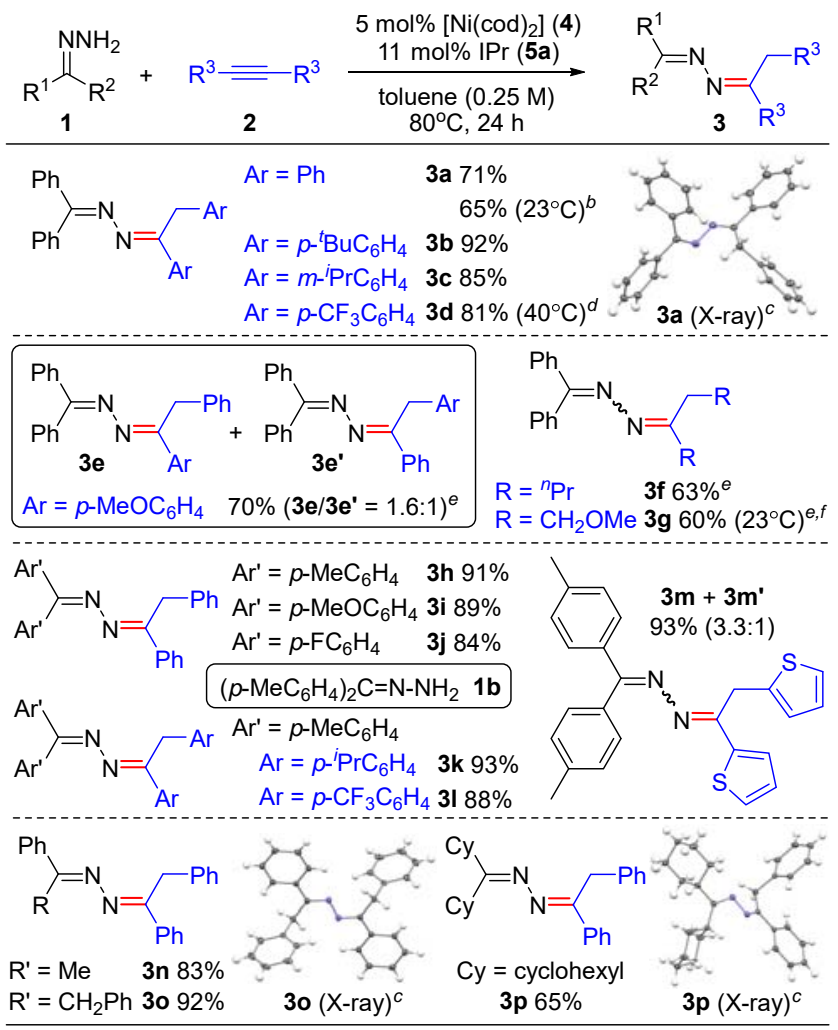

${ }^{a}$ General conditions: 1 ( 0.50 mmol, 1.0 equiv $), 2$ (1.2 equiv), 4 ( 0.05 equiv), 5a ( 0.11 equiv), toluene $(2.0 \mathrm{~mL}), 80^{\circ} \mathrm{C}, 24 \mathrm{~h}$; averaged isolated yield from two runs. ${ }^{b}$ Room-temperature reaction with $1.0 \mathrm{mmol} \mathrm{1,} 1.2 \mathrm{mmol} \mathrm{2,} 10 \mathrm{~mol} \%$ 4, $21 \mathrm{~mol} \%$ 5a; $96 \mathrm{~h}$. ${ }^{c}$ ORTEP diagram displayed as $40 \%$ probability ellipsoids. ${ }^{d}$ Slow addition protocol: alkyne was added portion-wise ( $4 \times 0.3$ equiv) over $6 \mathrm{~h} ; 40{ }^{\circ} \mathrm{C}$ reaction temperature. ${ }^{e}$ Yield is based on $\mathrm{GC}$ analysis of corresponding ketone from hydrolysis of ketazine product.

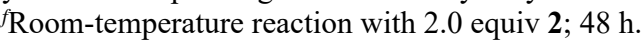

Scheme 2. Results from Reaction Mechanism Studies.

(a) Isolation of an IPr-ligated $\mathrm{Ni}(\mathrm{II})$ hydrazonate dimer (7a)

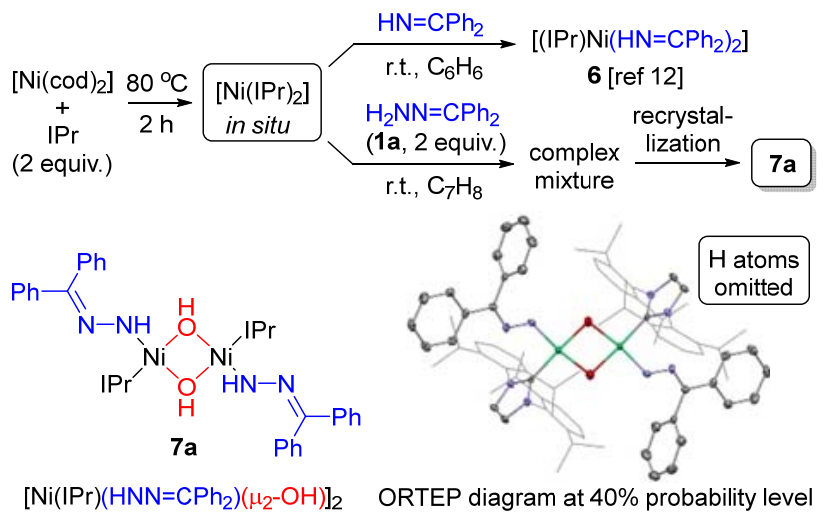

(b) Proposed mechanism for formation of hydrazonate $7 \mathbf{a}$

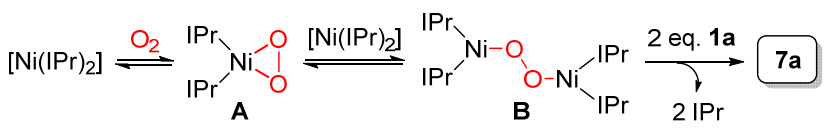

(c) Evaluation of $7 \mathrm{a}$ as pre-catalyst for alkyne hydrohydrazonation

\begin{tabular}{|c|c|c|c|c|c|c|}
\hline $\mathrm{Ph}$ & & & \multicolumn{2}{|c|}{ cat. $7 a$} & & \\
\hline $\begin{array}{c}1 \mathrm{a} \\
1.0 \text { equiv }\end{array}$ & & $\begin{array}{c}2 \mathbf{a} \\
2 \text { equiv }\end{array}$ & toluer & & & ${ }_{3 a}^{N=}$ \\
\hline $\begin{array}{c}1 \mathbf{a} \\
\text { Amount }\end{array}$ & $\begin{array}{l}\text { Toluene } \\
\text { Volume }\end{array}$ & $\begin{array}{c}7 \mathbf{a} \\
\text { Loading }\end{array}$ & Temp. & Time & $\begin{array}{c}\mathrm{GC} \\
\text { yield }\end{array}$ & $\begin{array}{l}\text { Isolated } \\
\text { Yield }\end{array}$ \\
\hline & $2 \mathrm{~mL}$ & $0.5 \mathrm{~mol} \%$ & $80^{\circ} \mathrm{C}$ & $24 \mathrm{~h}$ & & $73 \%$ \\
\hline & $5 \mathrm{~mL}$ & $0.5 \mathrm{~mol} \%$ & $80^{\circ} \mathrm{C}$ & $48 \mathrm{~h}$ & & \\
\hline & $5 \mathrm{~mL}$ & $5 \mathrm{~mol} \%$ & r.t. $\left(23^{\circ} \mathrm{C}\right)$ & $48 \mathrm{~h}$ & $78 \%$ & $71 \%(664$ \\
\hline
\end{tabular}

(d) Proposed catalytic cycle with $\mathrm{Ni}(\mathrm{II})$ hydrazonate dimer (7) as pre-catalyst

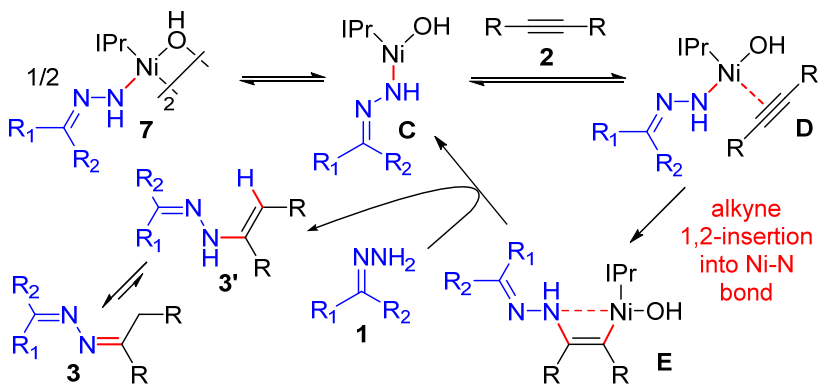

\section{ASSOCIATED CONTENT}

Supporting Information. Detailed experimental procedures, spectral data, and CIF files for reported single crystals.

\section{AUTHOR INFORMATION}

\section{Corresponding Author}

Pinjing Zhao - Department of Chemistry and Biochemistry, North Dakota State University, Fargo, ND 58108-6050, USA; orcid.org/0000-0002-5846-6271; Email: pinjing.zhao@ndsu.edu.

\section{Authors}

Jian Wang - School of Pharmacy, Hangzhou Medical College, No. 481, Binwen Road, Hangzhou 310000, China; orcid.org/00000003-1190-5799

Junfeng Liu - Department of Chemistry and Biochemistry, North Dakota State University, Fargo, ND 58108-6050, USA; orcid.org/0000-0002-4773-0786

Rajith S. Manan - Department of Chemistry and Biochemistry, North Dakota State University, Fargo, ND 58108-6050, USA; orcid.org/0000-0001-7081-0138 
Angel Ugrinov - Department of Chemistry and Biochemistry, North Dakota State University, Fargo, ND 58108-6050, USA; orcid.org/0000-0002-4284-6923

Taehyun Kim - Department of Chemistry and Biochemistry, North Dakota State University, Fargo, ND 58108-6050, USA Yanxiong Pan - Department of Chemistry and Biochemistry, North Dakota State University, Fargo, ND 58108-6050, USA; orcid.org/0000-0001-7084-8048

Zhongyu Yang - Department of Chemistry and Biochemistry, North Dakota State University, Fargo, ND 58108-6050, USA; orcid.org/0000-0002-3018-3608

\section{Author Contributions}

J.W., J.L. and R.S.M. performed the reported experiments and data analysis. T.K. assisted in substrate preparation and initial catalyst development. A.U. conducted X-ray crystallography tests and data analysis. Y.P. and Z.Y. provided technical support on $\mathrm{Ni}$ complex characterization. J.W., R.S.M. and P.Z. designed the catalytic sequence and developed the reaction conditions. P.Z. prepared this manuscript with feedback from J.W. and J.L.

\section{Notes}

The authors declare no competing financial interests.

\section{ACKNOWLEDGMENT}

Financial support for this work was provided by NSF (CHE1800467 for J.L. and P.Z.) and NIH (1R15GM120688-01 for J.W. R.S.M. and T.K.). Y.P. and Z.Y. thank NDSU Department of Chemistry and Biochemistry for a startup grant.

\section{REFERENCES}

(1) For recent reviews, see: (a) Kölmel, D. K.; Kool, E. T., Oximes and Hydrazones in Bioconjugation: Mechanism and Catalysis. Chem. Rev. 2017, 117 (15), 10358-10376. (b) Kobayashi, S.; Mori, Y.; Fossey, J. S.; Salter, M. M., Catalytic Enantioselective Formation of C-C Bonds by Addition to Imines and Hydrazones: A Ten-Year Update. Chem. Rev. 2011, 111, 2626-2704. (c) Xie, J.-H.; Zhu, S.-F.; Zhou, Q.-L., Transition Metal-Catalyzed Enantioselective Hydrogenation of Enamines and Imines. Chem. Rev. 2011, 111, 17131760. (d) Lazny, R.; Nodzewska, A., N,N-Dialkylhydrazones in Organic Synthesis. From Simple N,N-Dimethylhydrazones to Supported Chiral Auxiliaries. Chem. Rev. 2010, 110, 1386-1434. (e) Belskaya, N. P.; Dehaen, W.; Bakulev, V. A., Synthesis and properties of hydrazones bearing amide, thioamide and amidine functions. ARKIVOC 2010, 275-332.

(2) (a) Lewis, D. E., The Wolff-Kishner Reduction and Related Reactions. Discovery and Development. Elsevier: Amsterdam, 2019. (b) Kuethe, J. T.; Childers, K. G.; Peng, Z.; Journet, M.; Humphrey, G. R.; Vickery, T.; Bachert, D.; Lam, T. T., A Practical, KilogramScale Implementation of the Wolff-Kishner Reduction. Org. Process Res. Dev. 2009, 13, 576-580. (c) Wang, H.; Dai, X.-J.; Li, C.-J., Aldehydes as alkyl carbanion equivalents for additions to carbonyl compounds. Nature Chem. 2017, 9, 374-378.

(3) (a) Hartwig, J. F., Synthesis, structure, and reactivity of a palladium hydrazonato complex: a new type of reductive elimination reaction to form $\mathrm{C}-\mathrm{N}$ bonds and catalytic arylation of benzophenone hydrazone. Angew. Chem., Int. Ed. 1998, 37, 2090-2093. (b) Wagaw, S.; Yang, B. H.; Buchwald, S. L., A Palladium-Catalyzed Strategy for the Preparation of Indoles: A Novel Entry into the Fischer Indole Synthesis. J. Am. Chem. Soc. 1998, 120, 6621-6622. (c) Ferretti, A. C.; Mathew, J. S.; Ashworth, I.; Purdy, M.; Brennan, C.; Blackmond, D. G., Mechanistic inferences derived from competitive catalytic reactions: $\mathrm{Pd}$ (binap)-catalyzed amination of aryl halides. Adv. Synth. Catal. 2008, 350, 1007-1012. (d) Wu, W.; Fan, X.-H.; Zhang, L.-P.; Yang, L.-M., Nickel-catalyzed N-arylation of benzophenone hydrazone with bromoarenes. RSC Adv. 2014, 4, 3364-3367.

(4) Representative recent reviews on transition metal-catalyzed hydroamination with NH-nucleophiles: (a) Huang, L.; Arndt, M.;
Goossen, K.; Heydt, H.; Goossen, L. J., Late Transition MetalCatalyzed Hydroamination and Hydroamidation. Chem. Rev. 2015 , 115, 2596-2697. (b) Yim, J. C. H.; Schafer, L. L., Efficient antiMarkovnikov-selective catalysts for intermolecular alkyne hydroamination. Recent advances and synthetic applications. Eur. J. Org. Chem. 2014, 2014, 6825-6840. (c) K Hesp, K. D.; Stradiotto, M., Rhodium- and iridium-catalyzed hydroamination of alkenes. ChemCatChem 2010, 2, 1192-1207. (d) Müller, T. E.; Hultzsch, K. C.; Yus, M.; Foubelo, F.; Tada, M., Hydroamination: Direct Addition of Amines to Alkenes and Alkynes. Chem. Rev. 2008, 108, 37953892. (e) Widenhoefer, R. A.; Han, X., Gold-catalyzed hydroamination of C-C multiple bonds. Eur. J. Org. Chem. 2006, 4555-4563.

(5) Representative examples: (a) Benedetti, E.; Lemiere, G.; Chapellet, L.-L.; Penoni, A.; Palmisano, G.; Malacria, M.; Goddard, J.-P.; Fensterbank, L., Gold(I)-Catalyzed Cyclization of $\beta$ Allenylhydrazones: An Efficient Synthesis of Multisubstituted NAminopyrroles. Org. Lett. 2010, 12, 4396-4399. (b) Nakamura, I.; Shiraiwa, N.; Kanazawa, R.; Terada, M., Copper-Catalyzed Rearrangement of (Z)-Propynal Hydrazones via N-N Bond Cleavage. Org. Lett. 2010, 12, 4198-4200. (c) Kinjo, R.; Donnadieu, B.; Bertrand, G., Gold-Catalyzed Hydroamination of Alkynes and Allenes with Parent Hydrazine. Angew. Chem. Int. Ed. 2011, 50, 5560-5563. (d) Zora, M.; Kivrak, A., Synthesis of pyrazoles via CuImediated electrophilic cyclizations of $\alpha, \beta$-alkynic hydrazones. J. Org. Chem. 2011, 76, 9379-9390.

(6) Representative examples of intramolecular alkene hydrohydrazonation that are not based on organotransition metal catalysis: (a) (photoredox catalysis) Hu, X.-Q.; Chen, J.-R.; Wei, Q.; Liu, F.-L.; Deng, Q.-H.; Beauchemin, A. M.; Xiao, W.-J., Photocatalytic Generation of N-Centered Hydrazonyl Radicals: A Strategy for Hydroamination of $\beta, \gamma$-Unsaturated Hydrazones. Angew. Chem., Int. Ed. 2014, 53, 12163-12167. (b) (Brønsted base promotion) Peng, X.; Kaga, A.; Hirao, H.; Chiba, S., Hydroamination of alkenyl $\mathrm{N}$-arylhydrazones mediated by t-BuOK for the synthesis of nitrogen heterocycles. Org. Chem. Front. 2016, 3, 609-613. (c) (Brønsted acid promotion) He, H.; Xu, N.; Zhang, H.; Chen, B.; Hu, Z.; Guo, K.; Chun, J.; Cao, S.; Zhu, Y., Brønsted acid-promoted hydroamination of unsaturated hydrazones: access to biologically important 5-arylpyrazolines. RSC Advances 2021, 11, 17340-17345.

(7) Aza-Michael additions by $\mathrm{NH}_{2}$-hydrazones to activated (electron-deficient) alkynes have been reported. See a recent example under Rh-catalyzed conditions: Zhang, S.; Huang, D.; Xu, G.; Cao, S.; Wang, R.; Peng, S.; Sun, J., An efficient synthesis of isoquinolines via rhodium-catalyzed direct $\mathrm{C}-\mathrm{H}$ functionalization of arylhydrazines. Org. Biomol. Chem. 2015, 13, 7920-7923.

(8) For a Pd-catalyzed diene hydrohydrazonation via allylic substitution, see: Perrier, A.; Ferreira, M.; Reek, J. N. H.; van der Vlugt, J. I., Regioselective Pd-catalyzed hydroamination of substituted dienes. Catal. Sci. Technol. 2013, 3, 1375-1379.

(9) $\mathrm{Au}$ - and $\mathrm{Cu}$-catalyzed hydrohydrazonation of terminal alkynes with $\mathrm{NH}_{2}$-hydrazones that were isolated or in situ generated via parent hydrazine-based hydroamination: (a) Tolentino, D. R.; Jin, L.; Melaimi, M.; Bertrand, G., Mesoionic Carbene-Gold(I) Catalyzed Bis-Hydrohydrazination of Alkynes with Parent Hydrazine. Chem. Asian J. 2015, 10, 2139-2142. (b) Peltier, J. L.; Jazzar, R.; Melaimi, M.; Bertrand, G., Ancillary ligand-free copper catalysed hydrohydrazination of terminal alkynes with $\mathrm{NH}_{2} \mathrm{NH}_{2}$. Chem. Commun. 2016, 52, 2733-2735. (c)

(10) Additional examples of Au-catalyzed alkyne hydrohydrazination with high catalytic reactivity: (a) Duan, H.; Sengupta, S.; Petersen, J. L.; Akhmedov, N. G.; Shi, X., Triazole$\mathrm{Au}(\mathrm{I})$ Complexes: A New Class of Catalysts with Improved Thermal Stability and Reactivity for Intermolecular Alkyne Hydroamination. $J$. Am. Chem. Soc. 2009, 131, 12100-12102. (b) Lopez-Gomez, M. J.; Martin, D.; Bertrand, G., Anti-Bredt N-heterocyclic carbene: an efficient ligand for the gold(I)-catalyzed hydroamination of terminal alkynes with parent hydrazine. Chem. Commun. 2013, 49, 4483-4485. (c) Manzano, R.; Wurm, T.; Rominger, F.; Hashmi, A. S. K., Roomtemperature hydrohydrazination of terminal alkynes catalyzed by saturated abnormal N-heterocyclic carbene-gold(I) complexes. Chem. 
Eur. J. 2014, 20, 6844-6848. (d) Rotta-Loria, N. L.; Chisholm, A. J.; MacQueen, P. M.; McDonald, R.; Ferguson, M. J.; Stradiotto, M., Exploring the influence of phosphine ligation on the gold-catalyzed hydrohydrazination of terminal alkynes at room temperature. Organometallics 2017, 36, 2470-2475.

(11) Representative reports on Ti-catalyzed alkyne hydrohydrazination: (a) Cao, C.; Shi, Y.; Odom, A. L., Intermolecular Alkyne Hydroaminations Involving 1,1-Disubstituted Hydrazines. Org. Lett. 2002, 4, 2853-2856. (b) Banerjee, S.; Barnea, E.; Odom, A L., Titanium-Catalyzed Hydrohydrazination with Monosubstituted Hydrazines: Catalyst Design, Synthesis, and Reactivity. Organometallics 2008, 27, 1005-1014. (c) Yim, J. C.-H.; Bexrud, J. A.; Ayinla, R. O.; Leitch, D. C.; Schafer, L. L., Bis(amidate)bis(amido) Titanium Complex: A Regioselective Intermolecular Alkyne Hydroamination Catalyst. J. Org. Chem. 2014, 79, 2015-2028.

(12) Manan, R. S.; Kilaru, P.; Zhao, P., Nickel-Catalyzed Hydroimination of Alkynes. J. Am. Chem. Soc. 2015, 137, 6136-6139.

(13) (a) Chuang, S.-C.; Gandeepan, P.; Cheng, C.-H., Synthesis of Isoquinolines via $\mathrm{Rh}$ (III)-Catalyzed $\mathrm{C}-\mathrm{H}$ Activation Using Hydrazone as a New Oxidizing Directing Group. Org. Lett. 2013, 15, 5750-5753. (b) Huang, X.-C.; Yang, X.-H.; Song, R.-J.; Li, J.-H., RhodiumCatalyzed Synthesis of Isoquinolines and Indenes from Benzylidenehydrazones and Internal Alkynes. J. Org. Chem. 2014, 79, 1025-1031. (c) Pawar, A. B.; Agarwal, D.; Lade, D. M., $\mathrm{Cp} * \mathrm{Co}(\mathrm{III})-$ Catalyzed C-H/N-N Functionalization of Arylhydrazones for the Synthesis of Isoquinolines. J. Org. Chem. 2016, 81, 1140911415.

(14) For a leading review on mechanistically related [4+2] annulations for isoquinoline synthesis, see: He, R.; Huang, Z.-T.; Zheng, Q.-Y.; Wang, C., Isoquinoline skeleton synthesis via chelation-assisted C-H activation. Tetrahedron Lett. 2014, 55, 57055713 .

(15) Reported Ni-catalysts for alkyne hydroamination are rare and limited by low reactivity: (a) Campi, E. M.; Jackson, W. R., Preparation and reactions of rhodium complexes of some alkynylamines. J. Organomet. Chem. 1996, 523, 205-209. (b) Müller, T. E., Intramolecular catalytic addition of amines to alkynes. Tetrahedron Lett. 1998, 39, 5961-5962. (c) Reyes-Sanchez, A.; Canavera-Buelvas, F.; Barrios-Francisco, R.; Cifuentes-Vaca, O. L.; Flores-Alamo, M.; Garcia, J. J., Nickel-Catalyzed Transfer Semihydrogenation and Hydroamination of Aromatic Alkynes Using Amines As Hydrogen Donors. Organometallics 2011, 30, 3340-3345. (d) Reyes-Sanchez, A.; Garcia-Ventura, I.; Garcia, J. J., Easily available nickel complexes as catalysts for the intermolecular hydroamination of alkenes and alkynes. Dalton Trans. 2014, 43, $1762-1768$.

(16) (a) Safari, J.; Gandomi-Ravandi, S., Structure, synthesis and application of azines: a historical perspective. RSC Adv. 2014, 4, 46224-46249. (b) Le Goff, G.; Ouazzani, J., Natural hydrazinecontaining compounds: Biosynthesis, isolation, biological activities and synthesis. Biorg. Med. Chem. 2014, 22, 6529-6544. (c) Blair, L. M.; Sperry, J., Natural Products Containing a Nitrogen-Nitrogen Bond. J. Nat. Prod. 2013, 76, 794-812.

(17) Recent reviews on $\mathrm{Ni} / \mathrm{NHC}$ complexes and their catalytic applications: (a) Danopoulos, A. A.; Simler, T.; Braunstein, P., NHeterocyclic Carbene Complexes of Copper, Nickel, and Cobalt. Chem. Rev. 2019, 119, 3730-3961. (b) Ritleng, V.; Henrion, M.; Chetcuti, M. J., Nickel N-Heterocyclic Carbene-Catalyzed CHeteroatom Bond Formation, Reduction, and Oxidation: Reactions and Mechanistic Aspects. ACS Catal. 2016, 6, 890-906. (c) Prakasham, A. P.; Ghosh, P., Nickel N-heterocyclic carbene complexes and their utility in homogeneous catalysis. Inorg. Chim. Acta 2015, 431, 61-100. (d) Henrion, M.; Ritleng, V.; Chetcuti, M. J., Nickel N-Heterocyclic Carbene-Catalyzed C-C Bond Formation: Reactions and Mechanistic Aspects. ACS Catal. 2015, 5, 1283-1302.

(18) Meiries, S.; Speck, K.; Cordes, D. B.; Slawin, A. M. Z.; Nolan, S. P., [Pd(IPr*OMe)(acac)Cl]: Tuning the N-Heterocyclic Carbene in Catalytic C-N Bond Formation. Organometallics 2013, 32, 330-339.
(19) (a) Alphonse, P.; Moyen, F.; Mazerolles, P., Cyclotrimerization of alkynes catalyzed by nickel complexes formed in situ. J. Organomet. Chem. 1988, 345, 209-216. (b) Eisch, J. J.; Ma, X.; Han, K. I.; Gitua, J. N.; Krueger, C., Mechanistic Comparison of the Nickel(0)-Catalyzed Homo-Oligomerization and CoOligomerization of Alkynes and Nitriles, Eur. J. Inorg. Chem. 2001, 77-88. (c) Ogata, K.; Murayama, H.; Sugasawa, J.; Suzuki, N.; Fukuzawa, S.-I., Nickel-catalyzed highly regio- and stereoselective cross-trimerization between triisopropylsilylacetylene and internal alkynes leading to 1,3-diene-5-ynes. J. Am. Chem. Soc. 2009, 131, 3176-3177. (d) Horie, H.; Kurahashi, T.; Matsubara, S., Selective synthesis of trienes and dienes via nickel-catalyzed intermolecular cotrimerization of acrylates and alkynes. Chem. Commun. 2010, 46, 7229-7231.

(20) (a) Fleischer, S.; Werkmeister, S.; Zhou, S.; Junge, K.; Beller, M., Consecutive Intermolecular Reductive Hydroamination: Cooperative Transition-Metal and Chiral Bronsted Acid Catalysis. Chem. Eur. J. 2012, 18, 9005-9010, S9005/1-S9005/13. (b) Lavallo, V.; Wright, J. H., II; Tham, F. S.; Quinlivan, S., Perhalogenated Carba-closo-dodecaborate Anions as Ligand Substituents: Applications in Gold Catalysis. Angew. Chem., Int. Ed. 2013, 52, 3172-3176. (c) Yang, H.; Gabbai, F. P., Activation of a Hydroamination Gold Catalyst by Oxidation of a Redox-Noninnocent Chlorostibine Z-Ligand. J. Am. Chem. Soc. 2015, 137, 13425-13432. (d) Liu, D.; Nie, Q.; Zhang, R.; Cai, M., Regiospecific Hydroamination of Unsymmetrical Electron-Rich and Electron-Poor Alkynes with Anilines Catalyzed by Gold(I) Immobilized in MCM41. Adv. Synth. Catal. 2018, 360, 3940-3948.

(21) Terminal alkynes such as phenylacetylene failed to undergo desired hydroimination due to rapid oligomerization; see refs $12,19 \mathrm{c}$ and $19 \mathrm{~d}$ for related results with $\mathrm{Ni} / \mathrm{NHC}$ catalyst systems.

(22) Ketazine products that were unstable or isolated as inseparable isomeric mixtures were hydrolysed to generate corresponding ketones, which were analysed by calibrated GC for yield determination.

(23) GC analysis indicated high regioselectivity $(>10: 1)$ that favors anti-Markovnikov hydrohydrazonation products from aryl-alkyl alkynes. However, further catalyst development is needed to improve ketazine yields and enable reliable determination of regioselectivity.

(24) The mixture of $\mathbf{3} \mathbf{m} / \mathbf{3} \mathbf{m}$ ' was inseparable and the product ratio was determined by ${ }^{1} \mathrm{H}$ NMR without assignment of absolute configurations. The $(E)$-isomer is likely the major product due to its higher stability considering similar (yet less pronounced) steric factors as observed with other ketazine products.

(25) For a recent review on stereochemistry of Ni-catalyzed alkyne functionalization including discussion on E/Z-isomerization processes of Ni-alkenyl intermediates, see: Bottcher, S. E.; Hutchinson, L. E.; Wilger, D. J., Nickel-Catalyzed anti-Selective Alkyne Functionalization Reactions. Synthesis 2020, 52 (19), 2807-2820.

(26) See refs 3a for the X-ray structure of a bis(phosphine)-ligated mononuclear Pd(II) hydrazonato complex with $2.04 \AA$ Pd-N bond length.

(27) (a) Diez-Gonzalez, S.; Marion, N.; Nolan, S. P., NHeterocyclic Carbenes in Late Transition Metal Catalysis. Chem. Rev. 2009, 109, 3612-3676. (b) Scheuermann, M. L.; Goldberg, K. I., Reactions of Pd and Pt Complexes with Molecular Oxygen. Chem. Eur. J. 2014, 20, 14556-14568.

(28) Konnick, M. M.; Guzei, I. A.; Stahl, S. S., Characterization of Peroxo and Hydroperoxo Intermediates in the Aerobic Oxidation of N-Heterocyclic-Carbene-Coordinated Palladium(0). J. Am. Chem. Soc. 2004, 126, 10212-10213.

(29) The toluene solvent in this study was purchased as an anhydrous reagent and used without further purification. For the reaction described in Scheme 2a, using toluene with or without purification by degassing with $\mathrm{N}_{2}$ gave similar results for isolation of complex $7 \mathbf{a}$.

(30) (a) Dible, B. R.; Sigman, M. S., Unusual Reactivity of Molecular Oxygen with $\pi$-Allylnickel(N-heterocyclic carbene) Chloride Complexes. J. Am. Chem. Soc. 2003, 125, 872-873. (b) Dible, B. R.; Sigman, M. S., Steric Effects in the Aerobic Oxidation 
of $\pi$-Allylnickel(II) Complexes with N-Heterocyclic Carbenes. Inorg. Chem. 2006, 45, 8430-8441.

(31) (a) Bohm, V. P. W.; Gstottmayr, C. W. K.; Weskamp, T.; Herrmann, W. A., Catalytic C-C bond formation through selective activation of C-F bonds. Angew. Chem., Int. Ed. 2001, 40, 3387-3389. (b) Dible, B. R.; Sigman, M. S.; Arif, A. M., Oxygen-Induced Ligand Dehydrogenation of a Planar Bis- $\mu$-Chloronickel(I) Dimer Featuring an NHC Ligand. Inorg. Chem. 2005, 44, 3774-3776.

(32) For recent reviews on alkene and alkyne insertions into metalheteroatom bonds, see: (a) Hanley, P. S.; Hartwig, J. F., Migratory Insertion of Alkenes into Metal-Oxygen and Metal-Nitrogen Bonds. Angew. Chem., Int. Ed. 2013, 52, 8510-8525. (b) Ananikov, V. P.; Beletskaya, I. P., Alkyne and alkene insertion into metal-heteroatom and metal-hydrogen bonds. The key stages of hydrofunctionalization process. Top. Organomet. Chem. 2013, 43 (Hydrofunctionalization), $1-19$.

(33) For a direct observation of DMAD $\left(\mathrm{CH}_{3} \mathrm{O}_{2} \mathrm{CC} \equiv \mathrm{CCO}_{2} \mathrm{CH}_{3}\right)$ reaction with a $\mathrm{Ni}(\mathrm{II})$ anilide to form isolated product from synaminometalation, see: VanderLende, D. D.; Abboud, K. A.; Boncella, J. M., Monomeric Nickel(II) Amido Complexes. Synthesis, Reactivity, and Dynamics. Inorg. Chem. 1995, 34, 5319-26.

(34) See ref $15 \mathrm{c}$ for a Ni-catalyzed alkyne hydroamination process via proposed alkyne insertion into $\mathrm{Ni}$-amide linkage.

(35) For a direct observation of alkyne insertion into early metalamido linkage, see: Leitch, D. C.; Turner, C. S.; Schafer, L. L., Isolation of Catalytic Intermediates in Hydroamination Reactions: Insertion of Internal Alkynes into a Zirconium-Amido Bond. Angew. Chem., Int. Ed. 2010, 49, 6382-6386, S6382/1-S6382/16.

(36) See Schemes S1 and S2 in Supporting Information for description of alternative catalytic cycles and corresponding regiochemistry comparison for alkyne hydrohydrazonation. 
Table of Content (TOC) Graphic

Nickel-Catalyzed Intermolecular Alkyne Hydrohydrazonation

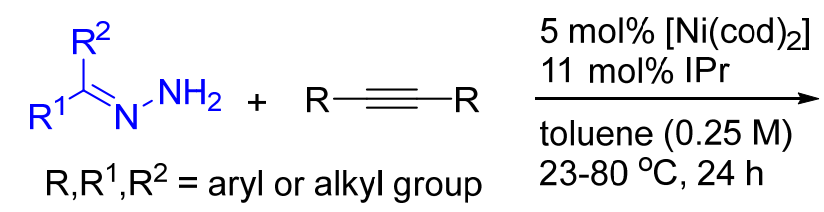<smiles>[R]CC([R])=NN=C([R])[R]</smiles>

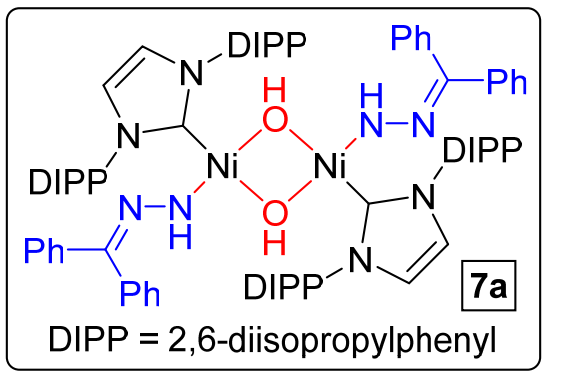

- 16 examples; up to $93 \%$ isolated yield

- atom-efficient synthesis of ketazines

- proposed C-N bond formation by alkyne insertion into $\mathrm{Ni}-\mathrm{N}$ bond

- isolated $\left[\mathrm{Ni}(\mathrm{IPr})\left(\mathrm{HNN}=\mathrm{CPh}_{2}\right)\left(\mu_{2}-\mathrm{OH}\right)\right]_{2}$ (7a) as highly active catalyst precursor 